\title{
Role of PKA in the process of neonatal cardiomyocyte hypertrophy induced by urotensin II
}

\author{
JIANRONG XU ${ }^{1}$, QINGHUA HAN ${ }^{1}$, HONGTAO SHI $^{1}$, WENYUAN LIU ${ }^{1}$, TINGTING CHU ${ }^{2}$ and HAO LI \\ ${ }^{1}$ Department of Cardiology, The First Hospital of Shanxi Medical University, Taiyuan, Shanxi 030001; \\ ${ }^{2}$ Department of Cardiology, Linfen People's Hospital, Linfen, Shanxi 041000, P.R. China
}

Received January 17, 2016; Accepted June 8, 2017

DOI: $10.3892 /$ ijmm.2017.3038

\begin{abstract}
The model of urotensin II (UII)-induced cardiomyocyte hypertrophy has been widely used in studies on hypertrophy. However, the molecular mechanisms responsible for UII-induced cardiomyocyte hypertrophy have not yet been fully elucidated. It has been demonstrated that cardiomyocyte hypertrophy induced by UII is associated with changes in the intracellular $\mathrm{Ca}^{2+}$ concentration. In the present study, we investigated whether the cAMP-dependent protein kinase A (PKA)-mediated upregulation of the phosphorylation levels of phospholamban (PLN) at Ser16 contributes to UII-induced cardiomyocyte hypertrophy. After primary cultures of neonatal rat cardiomyocytes were exposed to UII for $48 \mathrm{~h}$, cell size, protein/DNA contents and intracellular $\mathrm{Ca}^{2+}$ levels were detected. Western blot analysis was used to quantify the phosphorylated and total forms of PKA, PLN and the total amount of sarco/endoplasmic reticulum $\mathrm{Ca}^{2+}$-ATPase (SERCA)2a. UII increased the cell size, the protein/DNA ratio and the intracellular $\mathrm{Ca}^{2+}$ levels, consistent with the characteristics of hypertrophic response. In addition, exposure to UII upregulated the phosphorylation levels of PKA, and the expression levels of its downstream proteins, PLN and SERCA2a. However, treatment with PKA inhibitor (KT-5720) reversed all these effects of UII. On the whole, our results suggest that UII induces cardiomyocyte hypertrophy through the PKA-mediated upregulation of PLN phosphorylation at Ser16, which provides a new experimental foundation for the prevention and/or treatment of cardiac hypertrophy.
\end{abstract}

\section{Introduction}

Cardiac hypertrophy is not only a major risk factor in the development of heart failure, but also an independent risk factor for cardiac morbidity and mortality $(1,2)$. The incidence rate of myocardial hypertrophy is $>1 / 500$ in the general popula-

Correspondence to: Professor Qinghua Han, Department of Cardiology, The First Hospital of Shanxi Medical University, 85 Jiefang Nanlu Road, Taiyuan, Shanxi 030001, P.R. China E-mail: biohanqinghua@sohu.com

Key words: urotensin II, neonatal cardiomyocytes, hypertrophy, protein kinase A, phospholamban, SERCA2a tion (3-5). Due to the increased workload, the vast majority of mammalian cardiomyocytes fail to divide soon after birth, and this leads to hypertrophic growth $(6,7)$. Several factors can lead to pathological cardiac hypertrophy, such as gene mutations, ischemic myocardial injury, diabetic cardiomyopathy, valvular dysfunction and neurohumoral activation $(8,9)$. Cardiomyocyte hypertrophy may be a compensatory response to the changes in the molecular and biochemical microenvironment, including pressure overload. However, clinical therapeutic strategies are still limited for the treatment of cardiac hypertrophy $(10,11)$. The better understanding of this disease may contribute to the development of novel and more effective therapeutic strategies. Thus, it is of great importance to determine the molecular mechanisms responsible for the development of cardiac hypertrophy in vitro.

Urotensin II (UII), an eleven amino acid cyclic peptide, was originally isolated from the urophysis of teleost fish, which exhibit full activity in different tissues, including the cardiovascular system (12). It has been demonstrated that UII is a potent vasoconstrictor. In addition, the expression of UII and its receptor has been shown to be increased in cardiac tissue from patients with congestive heart failure, which positively correlates with disease severity and inversely with cardiac function (13). It has been certified that UII-induced cardiac hypertrophy involves multiple signaling pathwaysis, including mitogen-activated protein kinase signaling pathways, extracellular signalregulated kinase (ERK), epidermal growth factor receptor transactivation $(14,15)$ and the Akt signaling pathways (16). UII elicits strong vasoconstriction via the mobilization of intracellular $\mathrm{Ca}^{2+}$, as well as through extracellular $\mathrm{Ca}^{2+}$ entry (17). It has been shown that UII applied in the absence of extracellular $\mathrm{Ca}^{2+}$ induces transient cytosolic $\mathrm{Ca}^{2+}$ release from the sarcoplasmic reticulum (SR) (18). Recent studies have demonstrated that UII-induced cardiomyocyte hypertrophy is associated with the changes in the intracellular $\mathrm{Ca}^{2+}$ concentration (19). However, the precise signaling mechanisms responsible for UII-induced cardiac hypertrophy remain to be elucidated.

The cAMP-dependent protein kinase A (PKA), a threonine/ serine kinase consists of two catalytic (C) and two regulatory $(\mathrm{R})$ subunits, each of which is capable of binding two cAMP molecules. With the binding to cAMP, specific conformation of the regulatory subunits occurs, causing the activation and release of catalytic subunits (20). In cardiomyocytes, phospholamban (PLN), a membrane protein, is the target of PKA, which inhibits the sarco/endoplasmic reticulum $\mathrm{Ca}^{2+}$-ATPase (SERCA). 
Unphosphorylated PLN binds SERCA, reduces calcium uptake and further generates muscle contraction. However, once PKA phosphorylates PLN at Ser16 in the cytoplasmic helix, phosphorylated PLN relieves SERCA inhibition and initiates muscle relaxation (21). The inhibition of $\mathrm{Ca}^{2+} /$ calcineurin-NFAT has been shown to be involved in the attenuation of cardiac hypertrophy in vitro and in vivo (22); thus, the PKA signaling pathway may play a role in the development of cardiac hypertrophy.

In cardiac muscle tissues, it has been demonstrated that calcium $\left(\mathrm{Ca}^{2+}\right)$ plays an important role in regulating the process of excitation-contraction coupling (ECC). When a depolarizing stimulus arrives at the sarcolemma, ECC is activated and opens L-type $\mathrm{Ca}^{2+}$ channels in the T-tubule region, leading to an influx of $\mathrm{Ca}^{2+}$ into the cytosol, and further facilitating the release of $\mathrm{Ca}^{2+}$ from the cardiac ryanodine receptor 2(RyR2), which is known as $\mathrm{Ca}^{2+}$-induced $\mathrm{Ca}^{2+}$ release $(23,24)$. An increase in the intracellular free $\mathrm{Ca}^{2+}$ concentration after the intracellular $\mathrm{Ca}^{2+}$ release stimulates the binding of $\mathrm{Ca}^{2+}$ to the troponin complex and exposes the myosin actin-binding site in the cytosol (24). The interaction between actin and myosin further facilitates the generation of the power stroke and muscular contraction. To initiate muscular relaxation, intracellular $\mathrm{Ca}^{2+}$ must be eliminated from the cytoplasm. There are four main transporters for $\mathrm{Ca}^{2+}$ re-uptake: sarcolemmal $\mathrm{Ca}^{2+}$-ATPase, $\mathrm{Na}^{+} / \mathrm{Ca}^{2+}$ exchanger, SERCA and mitochondrial $\mathrm{Ca}^{2+}$ uniporter (24). In mammals, SERCA is the main transporter to transport $\mathrm{Ca}^{2+}$ from the myoplasm into the SR (25). Moreover, $92 \%$ of $\mathrm{Ca}^{2+}$ in rodent hearts and $70 \%$ of $\mathrm{Ca}^{2+}$ in the human heart are removed via the SERCA pump $(25,26)$. Thus, there may be a tight association between intracellular $\mathrm{Ca}^{2+}$ and cardiomyocyte hypertrophy.

To date, at least to the best of our knowledge, the effect of UII on the PKA signaling pathway in cardiomyocytes has not been documented. In this study, we therefore aimed to determine whether UII-induced cardiomyocyte hypertrophy is associated with the activation of the PKA signaling pathway in an in vitro model, and whether PLN/SERCA is involved downstream. The treatment of cardiomyocytes with a PKA inhibitor (KT-5720), allowed us to identify the key role for the activation of PKA in UII-induced hypertrophy.

\section{Materials and methods}

Reagents and antibodies. Dulbecco's modified Eagle's medium (DMEM), tissue culture reagents and fetal calf serum (FCS) were purchased from Invitrogen Life Technologies (Carlsbad, CA, USA). Antidodies [anti-PKA (SAB1300370), anti-p-PKA (SAB4301240), anti-PLN (HPA026900), anti-p-PLN (SAB1305590) and anti-SERCA (S7199)] were purchased from Sigma-Aldrich (St. Louis, MO, USA). UII was obtained from Sigma-Aldrich. KT-5720 was obtained from Tocris Bioscience (Bristol, UK).

Neonatal cardiac myocyte culture and treatment protocol. We obtained ventricles from 1-day-old Sprague-Dawley (SD) rats and isolated cardiac myocytes through digestion. All of the experiments were performed in accordance with the Guide for the Care and Use of Laboratory Animals and approved by the ethics committee of Shanxi Medical University. Briefly, SD rats were anesthetized and decapitated. The ventricles were rapidly extracted and minced into sections in Hanks' balanced salt solu- tion and digested with $1 \%$ collagenase (Sigma-Aldrich) in an incubator with $5 \% \mathrm{CO}_{2}$ at $37^{\circ} \mathrm{C}$ for $15 \mathrm{~min}$. The cell suspension was centrifuged at $90 \mathrm{rpm}$ for $8 \mathrm{~min}$ and the supernatant was resuspended in PBS containing $15 \%$ fetal bovine serum (FBS) (both from Wisent, Inc., St-Jean-Baptiste, QC, Canada). The cells were cultured for $2 \mathrm{~h}$ to allow the fibroblasts to attach to the dish. Cardiomyocytes were collected from the supernatants and cultured with DMEM containing $1 \mathrm{~g} / \mathrm{l}$ glucose plus $10 \% \mathrm{FBS}$ and $1 \%$ penicillin/streptomycin (Gibco, Carlsbad, CA, USA). The cardiomyocytes were divided into 4 groups as follows: i) the control group, in which the cells were treated with PBS in $2 \mathrm{ml}$ DMEM complete medium as a placebo for $2 \mathrm{~h}$, and then with $2 \mathrm{ml}$ DMEM complete medium for $48 \mathrm{~h}$; ii) the UII group, in which the cells were treated with PBS in $2 \mathrm{ml}$ DMEM complete medium as a placebo for $2 \mathrm{~h}$, and then exposed to $100 \mathrm{nM}$ UII in $2 \mathrm{ml}$ DMEM complete medium for $48 \mathrm{~h}$; iii) the UII + KT-5720 group, in which the cells were treated with $5 \mu \mathrm{M}$ KT-5720 in $2 \mathrm{ml}$ DMEM complete medium for $2 \mathrm{~h}$, and then exposed to $100 \mathrm{nM}$ UII also in $2 \mathrm{ml}$ DMEM complete medium for $48 \mathrm{~h}$; and iv) the KT-5720 group, in which the cells were treated with $5 \mu \mathrm{M}$ KT-5720 in $2 \mathrm{ml} \mathrm{DMEM}$ complete medium for $2 \mathrm{~h}$, and then with $2 \mathrm{ml}$ DMEM complete medium for $48 \mathrm{~h}$.

Measurement of cellplanimetric area. To determine the involvement of the PKA signaling pathway in UII-induced cardiac hypertrophy, the cells were plated in 6-well plates at about $30 / \mathrm{cm}^{2}$ density. The cell grouping and culture were performed as mentioned above. The pre-treated cells were washed with PBS twice prior to fixation in $4 \%$ paraformaldehyde solution. After $10 \mathrm{~min}$, the residual paraformaldehyde solutions were removed with three $5 \mathrm{~min}$ washes of $0.1 \%$ Triton X-100 (v/v, in PBS). The cells were double-labeled with phalloidin (for F-actin labeling) conjugated with Alexa Fluor 488 (The Jackson Laboratory, Bar Harbor, ME, USA) and DAPI (Sigma-Aldrich) (for DNA nuclear labeling). Measurements were calibrated by the measurement of a known standard and results were determined from 3 independent experiments.

Measurement of protein/DNA content. The cells were collected and then split into 2 equal aliquots for total protein and DNA measurements. One aliquot was used to extract protein and the protein concentration was detected using a BCA protein assay (Pierce, Rockford, IL, USA) (27). The other aliquot was used to extract DNA and the DNA concentration was investigated using Hoechst 33258 with calf thymus DNA as a standard (both Sigma-Aldrich) (28). The ratio of protein to DNA was then calculated to estimate potential protein synthesis.

Detection of the intracellular $\mathrm{Ca}^{2+}$ concentration. For the measurement of the $\mathrm{Ca}^{2+}$ concentration, the cells in the 4 groups were incubated with $10 \mu \mathrm{M}$ of Fura-3AM (Molecular Probes, Eugene, OR, USA) in recording solution (in $\mathrm{mM}$ : $135 \mathrm{NaCl}$, 5.6 KCl, $1.8 \mathrm{CaCl}_{2}, 1.2 \mathrm{MgCl}_{2}, 10 \mathrm{HEPES}$, and 10 glucose, $\mathrm{pH}$ 7.4) for $30 \mathrm{~min}$ at $37^{\circ} \mathrm{C}$ and then washed in recording solution. The staining cells were then co-labeled with DAPI for DNA nuclear staining. The coverslips were mounted in a $1 \mathrm{ml}$ plastic chamber and observed under a confocal microscope (LSM510; Carl Zeiss, Thornwood, NY, USA) to measure fluorescence. Fluo-3AM was excited at $488 \mathrm{~nm}$, and fluorescence emission was measured using a 505- to 530-nm band-pass 

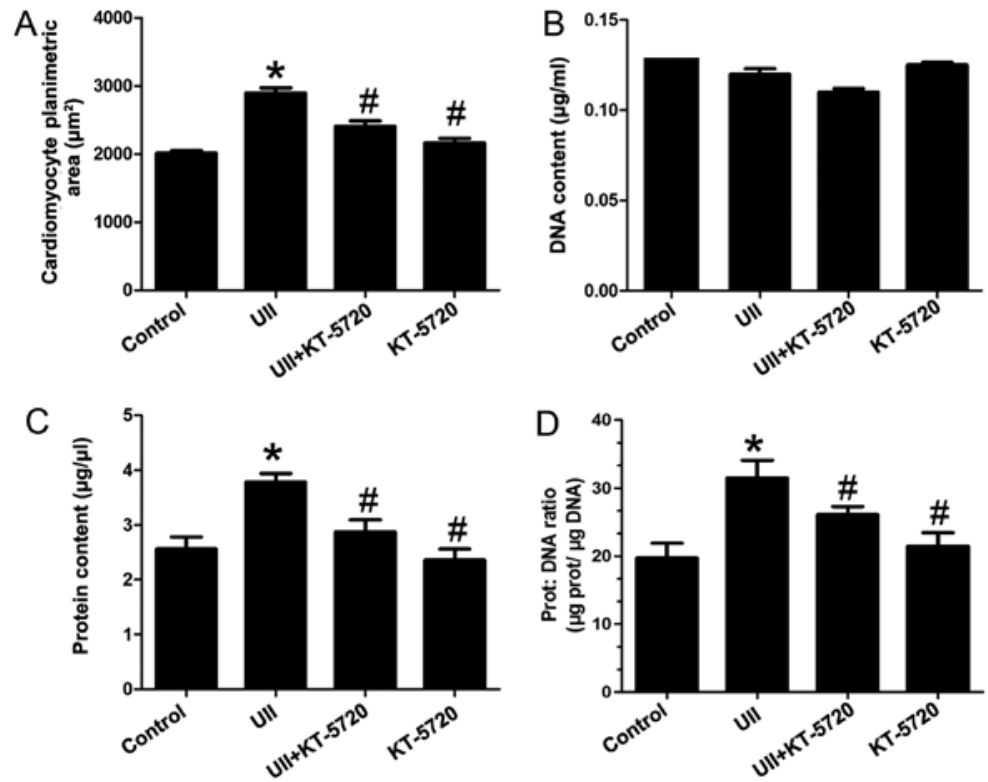

Figure 1. (A) Effects of the protein kinase A (PKA) inhibitor, KT-5720, on the cell planimetric area, (B) DNA and (C) protein content, (D) protein to DNA ratio, in cultured neonatal rat cardiomyocytes. ${ }^{*} \mathrm{p}<0.05$ vs. control group; ${ }^{*} \mathrm{p}<0.05$ vs. urotensin II (UII) group.

filter. Fluorescence images with Fura-3 AM and DAPI were collected and fluorescence quantification was carried out using the MetaFluor Imaging system (Molecular Devices).

Western blot analysis of protein expression. The cells were washed with cold PBS and the protein concentration was assessed using a BCA protein assay (Pierce). Proteins were separated on polyacrylamide gels and then electrotransferd onto nitrocellulose membranes (Amersham, Buckinghamshire, UK). After being blocked for $3 \mathrm{~h}$ in Tris-buffered saline with $0.1 \%$ Tween-20 (TBST) and 3\% bovine serum albumin (BSA), the membranes were incubated overnight at $4^{\circ} \mathrm{C}$ with an optimized dilution of 1:1,000 of rabbit polyclonal antibodies against phospho-PKA [p-PKA (Thr197)], PKA, phospho-PLN [p-PLN (serine-16)], PLN and SERCA2a. The membranes were then washed and incubated with alkaline phosphatase-conjugated secondary antibodies (SAB3700854; Sigma-Aldrich) in TBST for $2 \mathrm{~h}$ and developed with NBT/BCIP color substrate (Promega, Madison, WI, USA). The densities of the bands on the membranes were scanned and analyzed using an image analyzer (LabWorks Software; UVP, Upland, CA, USA).

Statistical analysis. Data are presented as the means \pm standard error of mean (SEM). Statistical analyses were performed using one-way analysis of variance (ANOVA), followed by adjusted t-tests with P-values corrected by the Newman-Keuls test. A p-value $<0.05$ was considered to indicate a statistically significant difference (two-tailed statistics). Data were analyzed using statistical package for social science (SPSS) (SPSS, Inc., Chicago, IL, USA) software version 14.0 for Microsoft Windows.

\section{Results}

KT-5720 inhibits UII-induced hypertrophy in neonatal rat cardiomyocytes. In order to gain further insight into the role played by UII and the effect of pre-treatment with KT-5720, the candomyocyte planimetric area, DNA content, protein content and protein/DNA ratio were measured. As shown in Fig. 1A and C, UII induced a significant increase in cell area and in the protein content, confirming the occurrence of cardiomyocyte hypertrophy compared with the untreated cells $(\mathrm{p}<0.05)$. On the contrary, the DNA content of the neonatal cardiomyocytes only changed slightly under the different treatment conditions (Fig. 1B; $p>0.05$ ). This led to a significant increase in the protein to DNA ratio in the UII-exposed cells, in comparison to the untreated cells (Fig. 1D; p<0.05). At the same time, pre-treatment of the UII-exposed cells with KT-5720 (a selective inhibitor of PKA) prevented the hypertrophic response. KT-5720 abolished the UII-induced increase in the cell area, protein content and protein to DNA ratio, suggesting that the PKA signaling pathway is involved in the effects of UII. Of note, neither UII nor the PKA inhibitor used exerted an effect on the DNA content. KT-5720 alone exerted similar effects as those observed with the co-incubation of UII and KT-5720.

KT-5720 decreases the high level of intracellular $\mathrm{Ca}^{2+}$ induced by UII in cardiomyocytes. To determine the mechanisms responsible for UII-induced cardiomyocyte hypertrophy, the double-labeling with DAPI and Fura-3AM immunofluorescence staining was applied to measure the intracellular $\mathrm{Ca}^{2+}$ intensity in cardiomyocytes. As is shown in Fig. 2A and B, UII induced a significant increase in the $\mathrm{Ca}^{2+}$ content in the cardiomyocytes compared with the control group. However, the effect of UII was markedly inhibited by pre-treatment with KT-5720. Incubation with KT-5720 alone exerted greater inhibitory effects than with co-incubation (UII and KT-5720) (Fig. 2C and D).

UII activates the PKA signaling pathway. We examined the involvement of the PKA signaling pathway in hypertrophy by western blot analysis. As is shown in Fig. 3, the protein expression level of p-PKA in the UII group was significantly increased compared with that in the control group. Pre-treatment with KT-5720 reversed this increasing phenomenon. KT-5720 incubation alone exerted similar effects as those observed with 


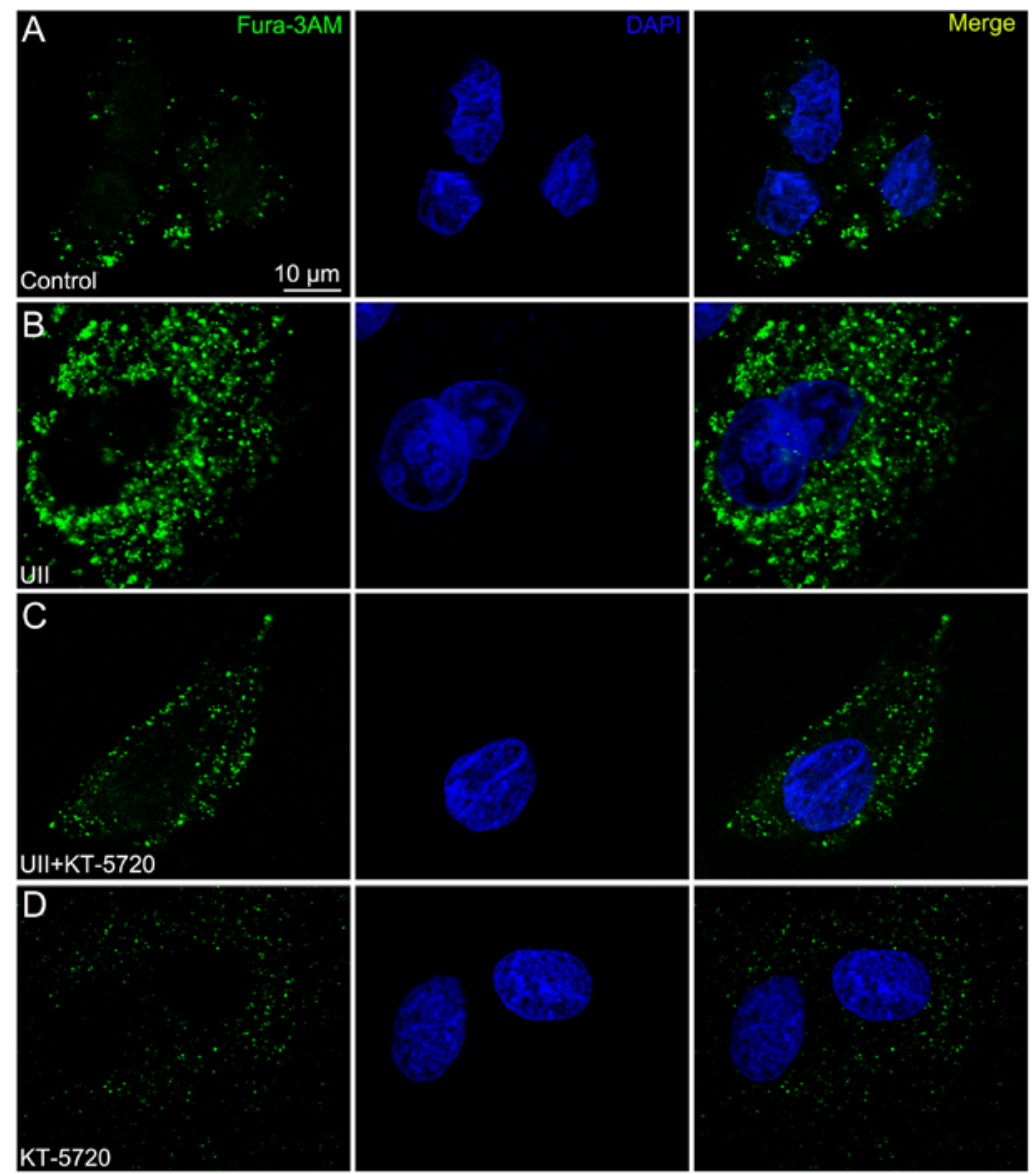

Figure 2. Effects of the protein kinase A (PKA) inhibitor, KT-5720, on intracellular $\mathrm{Ca}^{2+}$ (Fura-3AM) and nuclear (DAPI) double-labeled staining. Representative fluorescent micrographs of cardiomyocytes; intracellular $\mathrm{Ca}^{2+}$ is visualized with Alexa Fluor 488-conjugated Fura-3AM stain (green), whereas the nucleus is visualized by DAPI staining (blue); magnification, $\mathrm{x} 400$.

A
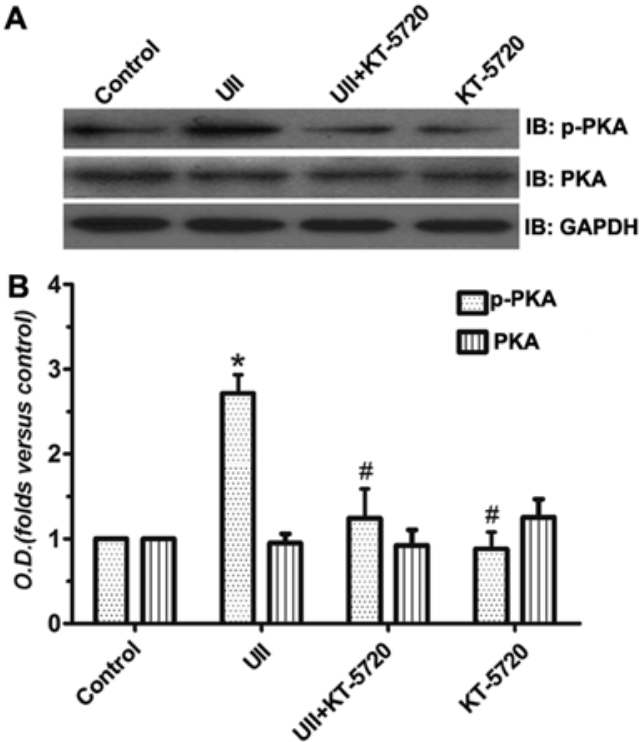

Figure 3. Effects of the protein kinase A (PKA) inhibitor, KT-5720, on the phosphorylation of PKA and total PKA. * $\mathrm{p}<0.05$ vs. control group; ${ }^{\#} \mathrm{p}<0.05$ vs. urotensin II (UII) group.

with co-incubation (UII and KT-5720). The total PKA protein expression remained unaltered. These data directly suggest that the PKA signaling pathway plays an important role in UII-induced cardiomyocyte hypertrophy.
Downstream mechanisms of PKA activation induced by UII. In cardiomyocytes, PLN phosphorylation at Ser16 by PKA is sufficient to reverse SERCA inhibition and increase the enzyme affinity for calcium that is pumped into the SR, initiating muscle relaxation (29). SERCA is a $110 \mathrm{kDa}$ membrane-embedded ATP-driven calcium pump and is regulated by intramembrane interaction with PLN.

In this study, in order to further investigate the downstream changes of p-PKA, the expression of PLN/SERCA was detected by western blot analysis. Compared with the control group, the results revealed that the p-PLN and SERCA2a bands were both dramatically increased in the cells incubated with UII (Figs. 4 and 5). The results also revealed that UII had did not affect the total PLN levels compared with the other groups. Pre-treatment with KT-5720 exerted an opposite effect to UII. Incubation with KT-5720 alone exerted similar effects as those observed with co-incubation (UII and KT-5720). These findings suggest that the PLN/SERCA2a signaling pathway is involved in the UII-induced neonatal cardiomyocyte hypertrophy by the regulation of the intracellular $\mathrm{Ca}^{2+}$ content.

\section{Discussion}

In this study, we demonstrated that UII-induced neonatal cardiomyocyte hypertrophy involves the phosphorylation of PKA. Calcium is the primary determinant of cardiac force 
A

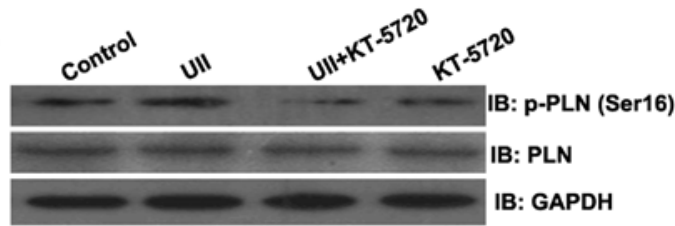

B

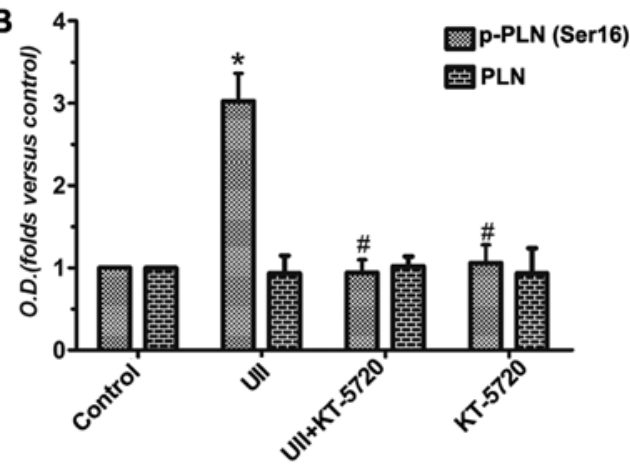

Figure 4. Effects of the protein kinase A (PKA) inhibitor, KT-5720, on the phosphorylation of phospholamban (PLN) and total PLN. * $<<0.05$ vs. control group; ${ }^{*} \mathrm{p}<0.05$ vs. urotensin II (UII) group, $\mathrm{n}=6$.

A
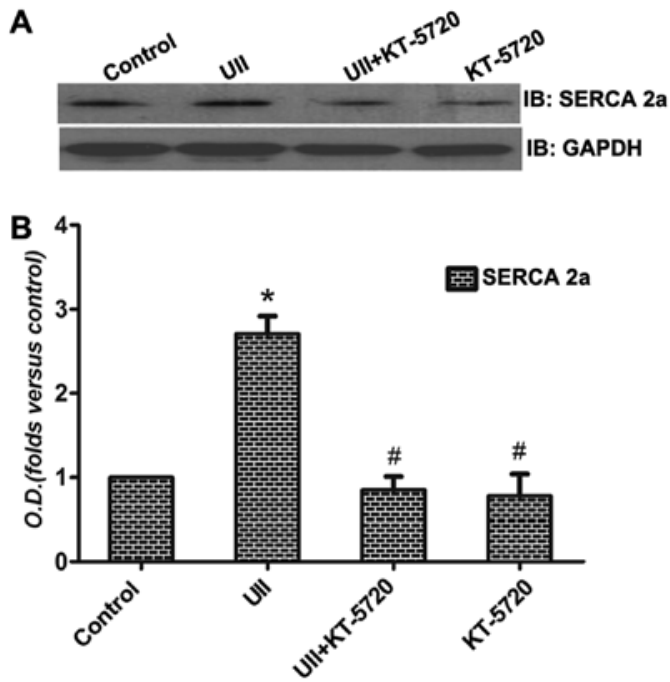

Figure 5. Effects of the protein kinase A (PKA) inhibitor, KT-5720, on SERCA2a expression in neonatal cardiomyocytes. " $\mathrm{p}<0.05$ vs. control group; ${ }^{\#} \mathrm{p}<0.05$ vs. urotensin II (UII) group.

production (30). Alterations in the phosphorylation levels of $\mathrm{Ca}^{2+}$-handing proteins downstream of PKA not only control myocardial contraction and relaxation, but also represent molecular signatures of failing hearts. UII is associated with cardiovascular function and may act as autocrine/paracrine neurohormonal factor within the heart. UII exerts inotropic effects via the G-protein-coupled receptor (GPCR) UTR in cardiac and peripheral vascular tissue. Stimulation of $\mathrm{G} \beta$ receptor prompts the activation of adenylyl cyclase, leading to an increase in the intracellular cAMP levels and finally, the activation of PKA. PKA substrate phosphorylation is involved in many cellular processes, such as gene expression, metabolism and contraction (31).

In cardiomyocytes, PKA phosphorylates many of the components associated with the excitation-coupling mechanism, including PLN. The phosphorylation of PLN promotes the relaxation of cardiomyocytes by accelerating $\mathrm{Ca}^{2+}$ re-uptake into the
SR by SERCA2a. The rise of cytosolic $\mathrm{Ca}^{2+}$ initiates contraction by the binding of $\mathrm{Ca}^{2+}$ to cardiac troponin $\mathrm{C}$, which in turn binds and displaces cardiac troponin I from its actin-binding site, thereby allowing myosin heads to interact with actin to form cross bridges (30). The sustained increase of intracellular $\mathrm{Ca}^{2+}$ levels induces left ventricular hypertrophy and dysfunction (32), which ultimately leads to the development of heart failure.

Even though cardiac hypertrophy is a compensatory response to external stimulation for maintaining the function of the heart, it is finally involved in disorders of contraction and relaxation (33). Many signaling pathways which respond to extracellular stimuli are involved in the molecular mechanisms of cardiomyocyte hypertrophy. It has been indicated that PKC, as one of the major signal transduction molecules, plays an significant role in regulating the differentiation and proliferation of different types of cells (34). It has been demonstrated that $\mathrm{Ca}^{2+}$ influx induced by PKA may activate the Raf-1/MAP kinase cascade (33). Our previous study has confirmed that CaMKII signaling pathway also plays an important role in UII-induced cardiomyocyte hypertrophy (35). In the present study, we demonstrate that PKA signaling also plays a crucial role in modulating intracellar $\mathrm{Ca}^{2+}$ influx through the phosphoPLN protein to maintain cardiac contractility. These data reinforce two possible roles of CaMKII and PKA signaling pathways as potential treatment agents in pathological cardiac hypertrophy. The activity of SERCA pump regulated by PLN is essential to preserve intracellar $\mathrm{Ca}^{2+}$ homeostasis and meet the physiological function requirements of the heart. In the future, we aim to focus on the effects of UII, its receptor, and the related signaling pathways in cardiac health and disease.

The effect of UII on the cardiovascular system has been investigated in vivo (36). Human UII (hUII) has also been used in the cynomolgus monkey to detect its cardiovascular effects (37). A complex dose-dependent hemodynamic response is excited after hUII systemic applications. Following exposure to $30-300 \mathrm{pmol} / \mathrm{kg}$ hUII, a marked systemic vasoconstriction and a severe myocardial contractile dysfunction occur, which differs from the effects of other vasoconstrictors, such as endothelin-1 (ET-1) and angiotensin (Ang)II (38). In addition, the effects of hUII have been investigated in rats (39). These results suggest that the increase in the levels of UII in myocardial cells leads to myocardial dysfunction under disease conditions, such as aortic stenosis (40). Taken together, our in vitro results, as well as other in vivo data demonstrate that UII induces significant cardiac hypertrophy.

In conclusion, the present study demonstrates that UII induces neonatal cardiomyocyte hypertrophy and this involves the activation of the PKA/PLN/SERCA2a signaling pathway. Our study established that the blockade of the PKA signaling pathway inhibits hypertrophy. These data provide a new experimental foundation for pathological cardiac hypertrophy, and may aid in the development of novel treatment strategies for cardiac hypertrophy.

\section{Acknowledgements}

This study was supported by grants from the Natural Science Foundation of Shanxi Province (no. 2012011036-1), the Shanxi Provincial Scientific Research Projects Foundation of Abroad-Studying Personnel (no. 2012-7), the Shanxi Provincial 
University Scientific Research Projects Foundation of AbroadStudying and Returning Personnel (no. 2011-63), the Selected Scientific Research Projects Foundation of Abroad-Studying Personnel, Office of Human Resources, Shanxi Province (no. 2013-68), the Selected Scientific Research Projects Foundation of Abroad-Studying and Returning Personnel, the Shanxi Province (no. 2010-97), Technology Innovation Foundation of Shanxi Medical University (no. 2010-7) and the Shanxi Provincial Scientific Research Projects Foundation of Abroad-Studying and Returning Personnel (no. 2009-9), the Technology Innovation Foundation of Shanxi Medical University (no. 01200912), the Shanxi Provincial University Scientific Research Projects Foundation of Abroad-Studying Personnel (no. 201128), and the Shanxi Provincial Technology Projects Foundation of Abroad-Studying Personnel (2012-084).

\section{References}

1. Levy D, Garrison RJ, Savage DD, Kannel WB and Castelli WP: Prognostic implications of echocardiographically determined left ventricular mass in the Framingham Heart Study. N Engl J Med 322: 1561-1566, 1990.

2. Tang S, Chen H, Cheng Y, Nasir MA, Kemper N and Bao E: The interactive association between heat shock factor 1 and heat shock proteins in primary myocardial cells subjected to heat stress. Int J Mol Med 37: 56-62, 2016.

3. Wu C, Dong S and Li Y: Effects of miRNA-455 on cardiac hypertrophy induced by pressure overload. Int J Mol Med 35: 893-900, 2015.

4. Liu P, Yan S, Chen M, Chen A, Yao D, Xu X, Cai X, Wang L and Huang X: Effects of baicalin on collagen I and collagen III expression in pulmonary arteries of rats with hypoxic pulmonary hypertension. Int J Mol Med 35: 901-908, 2015.

5. Chen P, Li F, Xu Z, Li Z and Yi XP: Expression and distribution of Src in the nucleus of myocytes in cardiac hypertrophy. Int J Mol Med 32: 165-173, 2013.

6. Heineke J and Molkentin JD: Regulation of cardiac hypertrophy by intracellular signalling pathways. Nat Rev Mol Cell Biol 7: $589-600,2006$

7. Guo H, Liu B, Hou L, The E, Li G, Wang D, Jie Q, Che W and Wei Y: The role of mAKAP $\beta$ in the process of cardiomyocyte hypertrophy induced by angiotensin II. Int J Mol Med 35: $1159-1168,2015$

8. Hill JA and Olson EN: Cardiac plasticity. N Engl J Med 358: 1370-1380, 2008.

9. Chuang CT, Guh JY, Lu CY, Chen HC and Chuang LY: S100B is required for high glucose-induced pro-fibrotic gene expression and hypertrophy in mesangial cells. Int J Mol Med 35: 546-552, 2015.

10. Zhang Y, Si Y and Ma N: Meis1 promotes poly (rC)-binding protein 2 expression and inhibits angiotensin II-induced cardiomyocyte hypertrophy. IUBMB Life 68: 13-22, 2015.

11. Zhou HM, Zhong ML, Zhang YF, Cui WY, Long CL and Wang $\mathrm{H}$ : Natakalim improves post-infarction left ventricular remodeling by restoring the coordinated balance between endothelial function and cardiac hypertrophy. Int J Mol Med 34: 1209-1218, 2014.

12. Gong H, Ma H, Liu M, Zhou B, Zhang G, Chen Z, Jiang G, Yan Y, Yang C, Kanda M, et al: Urotensin II inhibits the proliferation but not the differentiation of cardiac side population cells. Peptides 32: 1035-1041, 2011

13. Douglas SA, Tayara L, Ohlstein EH, Halawa N and Giaid A Congestive heart failure and expression of myocardial urotensin II. Lancet 359: 1990-1997, 2002.

14. Liu JC, Chen $\mathrm{CH}$, Chen JJ and Cheng TH: Urotensin II induces rat cardiomyocyte hypertrophy via the transient oxidization of Src homology 2-containing tyrosine phosphatase and transactivation of epidermal growth factor receptor. Mol Pharmacol 76: $1186-1195,2009$

15. Onan D, Pipolo L, Yang E, Hannan RD and Thomas WG: Urotensin II promotes hypertrophy of cardiac myocytes via mitogen-activated protein kinases. Mol Endocrinol 18: 2344-2354, 2004.

16. Gruson D, Ginion A, Decroly N, Lause P, Vanoverschelde JL, Ketelslegers JM, Bertrand L and Thissen JP: Urotensin II induction of adult cardiomyocytes hypertrophy involves the Akt/GSK-3beta signaling pathway. Peptides 31: 1326-1333, 2010.

17. Maguire JJ and Davenport AP: Is urotensin-II the new endothelin? Br J Pharmacol 137: 579-588, 2002.
18. Domínguez-Rodríguez A,Díaz I, Rodríguez-Moyano M,CalderónSánchez E, Rosado JA, Ordóñez A and Smani T: Urotensin-II signaling mechanism in rat coronary artery: role of STIM1 and Orail-dependent store operated calcium influx in vasoconstriction. Arterioscler Thromb Vasc Biol 32: 1325-1332, 2012.

19. Zhang Y, Ying J, Jiang D, Chang Z, Li H, Zhang G, Gong S, Jiang $X$ and Tao J: Urotensin-II receptor stimulation of cardiac L-type $\mathrm{Ca}^{2+}$ channels requires the $\beta \gamma$ subunits of $\mathrm{Gi} / \mathrm{o}$-protein and phosphatidylinositol 3-kinase-dependent protein kinase $\mathrm{C} \beta 1$ isoform. J Biol Chem 290: 8644-8655, 2015.

20. Rababa'h A, Singh S, Suryavanshi SV, Altarabsheh SE, Deo SV and McConnell BK: Compartmentalization role of A-kinase anchoring proteins (AKAPs) in mediating protein kinase A (PKA) signaling and cardiomyocyte hypertrophy. Int J Mol Sci 16: 218-229, 2014.

21. Masterson LR, Yu T, Shi L, Wang Y, Gustavsson M, Mueller MM and Veglia G: cAMP-dependent protein kinase A selects the excited state of the membrane substrate phospholamban. J Mol Biol 412: 155-164, 2011.

22. Yin Z, Wang X, Zhang L, Zhou H, Wei L and Dong X: Aspirin attenuates angiotensin II-induced cardiomyocyte hypertrophy by inhibiting the $\mathrm{Ca}(2+) /$ Calcineurin-NFAT signaling pathway. Cardiovasc Ther 34: 21-29, 2016.

23. Fabiato A: Calcium-induced release of calcium from the cardiac sarcoplasmic reticulum. Am J Physiol 245: C1-C14, 1983.

24. Bers DM: Cardiac excitation-contraction coupling. Nature 415: 198-205, 2002.

25. Bers DM: Ca transport during contraction and relaxation in mammalian ventricular muscle. Basic Res Cardiol 92 (Suppl 1): $1-10,1997$.

26. MacLennan DH and Kranias EG: Phospholamban: a crucial regulator of cardiac contractility. Nat Rev Mol Cell Biol 4: 566-577, 2003.

27. Zhang C, Shan XL, Liao YL, Zhao P, Guo W, Wei HC and Lu R: Effects of stachydrine on norepinephrine-induced neonatal rat cardiac myocytes hypertrophy and intracellular calcium transients. BMC Complement Altern Med 14: 474, 2014.

28. Giordano A, Romano S, Mallardo M, D'Angelillo A, Calì G, Corcione N, Ferraro P and Romano MF: FK506 can activate transforming growth factor-beta signalling in vascular smooth muscle cells and promote proliferation. Cardiovasc Res 79: 519-526, 2008.

29. Maclennan DH: Interactions of the calcium ATPase with phospholamban and sarcolipin: structure, physiology and pathophysiology. J Muscle Res Cell Motil 25: 600-601, 2004.

30. Irie T, Sips PY, Kai S, Kida K, Ikeda K, Hirai S, Moazzami K, Jiramongkolchai P, Bloch DB, Doulias PT, et al: S-nitrosylation of calcium-handling proteins in cardiac adrenergic signaling and hypertrophy. Circ Res 117: 793-803, 2015.

31. Walsh DA and Van Patten SM: Multiple pathway signal transduction by the cAMP-dependent protein kinase. FASEB J 8: 1227-1236, 1994.

32. Shioya T: A simple technique for isolating healthy heart cells from mouse models. J Physiol Sci 57: 327-335, 2007.

33. Yamazaki T, Komuro I, Zou Y, Kudoh S, Mizuno T, Hiroi Y, Shiojima I, Takano H, Kinugawa K, Kohmoto O, et al: Protein kinase A and protein kinase $\mathrm{C}$ synergistically activate the Raf-1 kinase/mitogen-activated protein kinase cascade in neonatal rat cardiomyocytes. J Mol Cell Cardiol 29: 2491-2501, 1997.

34. Komuro I and Yazaki Y: Control of cardiac gene expression by mechanical stress. Annu Rev Physiol 55: 55-75, 1993.

35. Shi H, Han Q, Xu J, Liu W, Chu T and Zhao L: Urotensin II induction of neonatal cardiomyocyte hypertrophy involves the CaMKII/PLN/SERCA 2a signaling pathway. Gene 583: 8-14, 2016.

36. Tölle $\mathrm{M}$ and van der Giet M: Cardiorenovascular effects of urotensin II and the relevance of the UT receptor. Peptides 29: 743-763, 2008 .

37. Douglas SA, Sulpizio AC, Piercy V, Sarau HM, Ames RS, Aiyar NV, Ohlstein EH and Willette RN: Differential vasoconstrictor activity of human urotensin-II in vascular tissue isolated from the rat, mouse, dog, pig, marmoset and cynomolgus monkey. Br J Pharmacol 131: 1262-1274, 2000

38. Bai XY, Liu XC, Yang Q, Tang XD and He GW: The interaction between human urotensin II and vasodilator agents in human internal mammary artery with possible clinical implications. Ann Thorac Surg 92: 610-616, 2011.

39. Shyu KG, Wang BW, Chen WJ, Kuan P and Lin CM: Angiotensin II mediates urotensin II expression by hypoxia in cultured cardiac fibroblast. Eur J Clin Invest 42: 17-26, 2012.

40. Hassan GS, Chouiali F, Saito T, Hu F, Douglas SA, Ao Z, Willette RN, Ohlstein EH and Giaid A: Effect of human urotensin-II infusion on hemodynamics and cardiac function. Can J Physiol Pharmacol 81: 125-128, 2003. 